\title{
COMUNIDADE VIRTUAL DE PRÁTICA: PERSPECTIVAS E DESAFIOS PARA A GESTÃO EDUCACIONAL DE CAMPINA GRANDE-PB
}

\author{
Luciana Kátia Reis ${ }^{1}$ \\ Mabel Ribeiro Petrucci ${ }^{2}$ \\ Sonia de Almeida Pimenta ${ }^{3}$ \\ Maria Severina Gomes Melo da Rocha ${ }^{4}$ \\ Danielli Cristina de Lima Silva ${ }^{5}$
}

\begin{abstract}
In this article, the first steps for the implementation of an online learning community are presented, in partnership with public education technicians from the municipality of Campina Grande, in the state of Paraíba, Brazil. In this paper, we analyse the aspects that stimulated us to develop collaborative training sessions through technological tools and networks, aimed at disseminating individual, as well as collective practices, together with supervisors and replicators from school units from the municipality. Thanks to this sort of dissemination, an online interaction was observed, and this fact extrapolated the time and space of live meetings. It is also the aim of this paper that such discussions highlight aspects, and actions that might contribute to the improvement of learning from the student's perspective, and, as a result, the improvement of the education as a whole in the municipality.
\end{abstract}

Keywords: Online learning community; Training for Educators; Pedagogical mediation

Resumo. Neste artigo são apresentados os primeiros passos para a implementação de uma Comunidade Virtual de Prática com técnicos educacionais da rede municipal de ensino de Campina Grande-PB, Brasil. Nele discorremos sobre os aspectos que nos impulsionaram a desenvolver, por meio de instrumental tecnológico e em rede, encontros formativos, em regime de colaboração e socialização das práticas individuais e coletivas, com os Supervisores e Orientadores Educacionais que atuam nas unidades escolares do nosso município. Objetiva-se, com estas comunidades, uma interação virtual que extrapole o tempo/espaço dos encontros presenciais, promovendo a continuidade das discussões demandadas pelos sujeitos, de modo a vislumbrar ações que contribuam para a qualificação da gestão educacional no município de modo a potencializar aprendizagens tanto dos estudantes, quanto dos professores e também dos gestores do município.

\footnotetext{
1 Secretaria de Educação, Campina Grande - PB - Brasil - lucianakreis@ yahoo.com.br

2 Departamento de Educação - Universidade Estadual da Paraíba (UEPB), Campina Grande - PB Brasil - petruccimabelribeiro@gmail.com

${ }^{3}$ Departamento de Metodologia da Educação - Universidade Federal da Paraíba (UFPB), João Pessoa PB - Brasil - sopimenta1@gmail.com

${ }^{4}$ Universidade da Madeira -Portugal, Brasil

5 Programa de Pós-Graduação em Linguística - PROLING - UFPB
} 
Palavras-chave: Comunidade Virtual de Prática; Formação de Educadores; Mediação Pedagógica

\section{Introdução}

Este artigo objetiva explicitar a construção de uma Comunidade Virtual de Prática de modo a atender às demandas formativas e informativas dos profissionais da Educação da rede municipal de Campina Grande - PB, os quais alegam que as oportunidades de formação continuada e de gestão na modalidade presencial são insuficientes e inadequadas para a realidade local.

A necessidade de construção e desenvolvimento de uma Comunidade Virtual de Prática no âmbito da Secretaria de Educação de Campina Grande-PB justifica-se pois é urgente implementar encontros formativos e informativos, com a Equipe Multiprofissional $^{6}$ que extrapolem o tempo/espaço dos encontros presenciais/mensais. Além disto, não há como estabelecer novos processos de gestão da educação e da aprendizagem reproduzindo modelos que já não atendem à realidade da vida em sociedade quer seja de professores, quer seja de estudantes. Parte-se do pressuposto de que para incrementar a qualidade na educação, é preciso ampliar os mecanismos de uma gestão democrática das escolas e dos saberes. Para tanto, é indispensável e irremediável a implantação de práticas colaborativas de gestão e de formação, visando estabelecer vínculos de parceria entre os técnicos educacionais que atuam nas escolas e creches.

Concorrendo positivamente para o uso das Tecnologias Digitais da Informação e Comunicação (TDIC) nos processos de melhoria da qualidade da educação, os técnicos da Equipe Multiprofissional cursaram e concluíram o curso Linux Educacional, promovido pelo MEC (Ministério da Educação) e receberam um notebook, que a priori objetiva contribuir como um instrumento a serviço do exercício pedagógico dos mesmos. Todavia, entendemos que o uso pedagógico destes recursos tecnológicos passa pela sua apropriação também no ato de planejar a prática pedagógica. É nesta perspectiva educacional que nossa proposta se insere.

As práticas circunscritas às Comunidades aqui propostas dizem respeito ao encaminhamento das atividades advindas da Secretaria de Educação do Município, a

\footnotetext{
${ }^{6}$ Equipe Multiprofissional- formada por profissionais efetivos da Rede Municipal graduados em Supervisão e Orientação Educacional, Psicologia e Assistente Social
}

RPI Revista de Pesquisa Interdisciplinar, Cajazeiras, v. 2, n. 2, 139-148, jun/dez. de 2017. 
exemplo das orientações e diretrizes para: a atualização dos Projetos Pedagógicos de cada unidade escolar que compõe a Rede Municipal, inclusive as creches; o planejamento e desenvolvimento das Paradas Totais ${ }^{7}$ com os professores e técnicos; a socialização e discussão de temas para o cronograma de encontros, dentre outros.

Vale salientar que a Comunidade Virtual de Prática possibilita inúmeras práticas mediadoras de gestores e da Equipe Multiprofissional do município de Campina Grande. Além disto, esta Tecnologia possibilita o acesso aos perfis de cada um dos integrantes da Comunidade, de modo que estes podem interagir entre si, expondo suas experiências profissionais, aceitando desafios do cotidiano escolar, buscando inovar em suas experiências particulares e coletivas, compartilhando novos saberes e sugerindo novos projetos.

\section{As TDIC na formação de educadores}

No mundo contemporâneo, as configurações políticas, econômicas e culturais necessitam ser repensadas em função das demandas provocadas pelo desenvolvimento tecnológico, a exemplo da relação entre a globalização e o uso intensivo de novas tecnologias que, ao tempo em que podem provocar o isolamento e a degradação, também podem viabilizar a democratização do acesso às informações e a produção do conhecimento.

As inovações tecnológicas e o impacto das mesmas sobre as diferentes culturas configuram o que Lévy (1999, p. 157) chama de "mutação contemporânea da relação com o saber”. Estas mutações são possíveis com maior intensidade no Ciberespaço, Neste, não cabe a perspectiva do saber como estoque, formatado e perpassado pelos livros como fonte única e inesgotável do saber e da informação. Nesta nova conjuntura, o saber absoluto passa a co-existir num espaço-tempo histórico com um saber mais fluido, menos denso, mais aberto e contínuo e menos linear.

Para este autor três constatações emergem a partir deste quadro de mutação do saber:

[...], a primeira constatação diz respeito à velocidade de surgimento e de renovação dos saberes e savoir-faire. [...]. A

\footnotetext{
${ }^{7}$ Parada Total- termo utilizado em nosso município para os encontros de professores e equipe técnica para o planejamento do bimestre escolar.
}

RPI Revista de Pesquisa Interdisciplinar, Cajazeiras, v. 2, n. 2, 139-148, jun/dez. de 2017. 
segunda constatação, fortemente ligada à primeira, diz respeito à nova natureza do trabalho, cuja parte de transação de conhecimentos não pára de crescer. Trabalhar quer dizer, cada vez mais, aprender, transmitir saberes e produzir conhecimentos. Terceira constatação: o ciberespaço suporta tecnologias intelectuais que amplificam, exteriorizam e modificam numerosas funções cognitivas humanas: memória (bancos de dados, hiperdocumentos, arquivos digitais de todos os tipos), imaginação (simulações), percepção (sensores digitais, telepresença, realidades virtuais), raciocínios (inteligência artificial, modelização de fenômenos complexos). (LÉVY, 1999, p.157)

Percebe-se que o avanço científico-tecnológico impõe ao sujeito novas aprendizagens para desenvolver competências e habilidades para não só atuar no mundo do trabalho, mas também - face às transformações histórico-culturais - para estabelecer relações com o saber que instituem um outro sujeito, que se admite ao mesmo tempo ensinante e aprendente.

Constata-se assim, que as exigências do mundo contemporâneo (complexo e mutável) promovem efeitos nos sujeitos que são de cunho cognitivo, social e discursivo. Tais efeitos são percebidos nas alterações promovidas nas relações sociais e nas instituições, de modo que sujeitos e instituições ocupam novas identidades e novos papéis, necessitando de um redimensionamento nos seus fazeres.

Neste contexto, é necessário possibilitar ao coletivo de educadores repensar sua prática pedagógica face aos desafios e finalidades da escola do século XXI, ao tempo em que possam, também, refletir, compreender e ressignificar sua identidade profissional. A esse respeito, Coelho (1996) propõe compreender a identidade profissional como uma construção no processo de formação, a partir do que os professores "têm a dizer: sobre si e sobre os outros" (COELHO, 1996, p. 52); ou seja, a construção da identidade profissional é um processo que se desenvolve culturalmente. Nessa perspectiva, o tema da formação permanente/continuada de educadores emerge da pungente necessidade de dialogar com conceitos que visam à construção de conhecimentos sobre a prática pedagógica e sobre os saberes necessários para ensinar frente às complexas relações que se estabelecem já neste início do século XXI.

Deste modo, abandona-se o conceito de formação permanente/continuada como forma de atualização por meio da aquisição de informações científicas, didáticas e 
disciplinares, descontextualizadas da prática educativa e das demandas do mundo contemporâneo, para referendar um conceito de formação que consiste em construir conhecimentos e teorias sobre a prática docente e pedagógica, a partir da reflexão crítica, assim como já anunciado por Freire (1996), Imbernón (2000), Morin (2010, 2000), Schön (2000), Tardif (2007), Perrenoud (2002) e outros.

Asseveramos que, face às configurações da sociedade contemporânea, as quais induzem e demandam mudanças nos processos de gestão e da aprendizagem, é urgente assumir abordagens na perspectiva sociocultural, dado que esta compreende as relações entre sujeitos e a realidade. Neste sentido, a construção e a análise da gestão e do fazer pedagógico, a partir da Comunidade Virtual de Prática configuram alternativas que podem contribuir para que o espaço escolar seja enriquecido com a troca de experiências, tornando-o mais orgânico e colaborativo, implicando assim na em metas de aprendizagem e qualidade do ensino.

Destaca-se também que, para fazer frente à pedagogia tradicional, há que se investir em práticas pedagógicas mediadoras, as quais devem se originar na própria formação inicial e continuada do professor. Ademais, a TDIC pode ser instrumento para incentivar as pessoas ao diálogo e à interatividade, dado que fornecem tempo maior para a reflexão antes da resposta do sujeito, bem como não o expõe ao ato de interlocução. Neste sentido, não há como negar o potencial das Tecnologias Digitais da Informação e Comunicação para a mediação pedagógica.

Cabe ressaltar também o potencial de interatividade que as Tecnologias Digitais da Informação e Comunicação oferecem, na medida em que possibilitam o enriquecimento com outros saberes sobre os temas em debate, qualificando então a participação dos sujeitos que podem, frente às tecnologias, mais do que apenas ligar os desligar, receber ou não uma informação - é possível interagir no sentido de buscar novas informações significativas e, assim, contribuir com a construção de um conhecimento socialmente válido.

Esta qualificação da interatividade possível com o uso das tecnologias e apropriada nas Comunidades Virtuais de Práticas amplia a capacidade de o sujeito agir referenciado pelas suas experiências e ancorando novos saberes às mesmas. Nestas, como em outras comunidades, a cultura e os saberes são os elos que as fortalecem, são a 
própria razão de ser de comunidades virtuais, nas quais as diferenças movem os seus fluxos. Nos dizeres de Gomez:

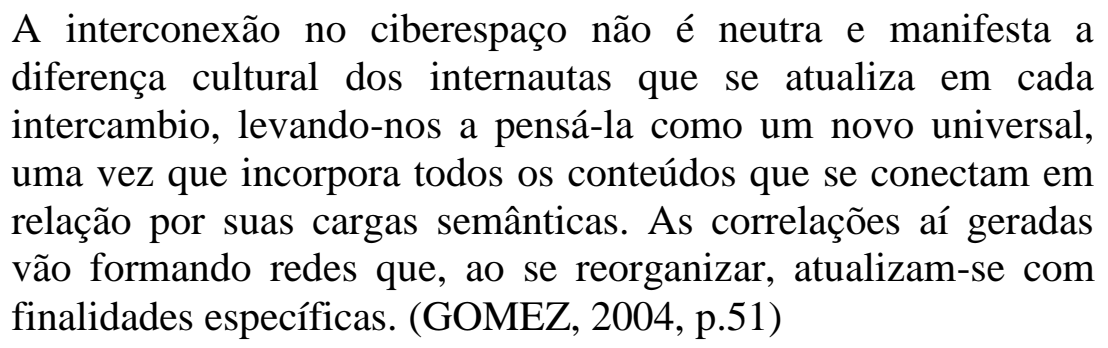

Um ambiente interativo não oportuniza somente o sim ou o não. Mas nele, o indivíduo pode percorrer o caminho que deseja, por isso, a mídia do ambiente virtual não tem começo nem fim. Portanto, a interatividade é mais que interação, é uma hiperinteração, uma bidirecionalidade (fusão emissão-recepção), para participação e intervenção, pois na medida em que um indivíduo se predispuser a uma relação hipertextual com outro indivíduo ocorre a interatividade. Podemos afirmar que a interatividade se constitui no momento em que uma mídia permite ao usuário exercer influência sobre o conteúdo ou a forma da comunicação mediada. Sendo assim, a interatividade no ambiente virtual possibilita a socialização entre sujeitos de diversas áreas do conhecimento, e deste modo a capacidade do sujeito interagir no ambiente virtual possibilita uma atuação crítica frente aos elementos constituintes da aprendizagem autônoma no mesmo.

\section{A Comunidade Virtual de Prática no âmbito educacional}

A Comunidade Virtual de Prática tem como foco principal as práticas de gestão e organização do trabalho pedagógico, fundamentadas na mediação e na interatividade que constituem o regime de colaboração entre os pares que definem e vivem o cotidiano escolar. Para tanto, é imprescindível que os setores organizacionais envolvidos na utilização das comunidades de prática disponibilizem os perfis de seus colaboradores, de modo a socializar em um determinado espaço as potencialidades de cada um a fim de que possam ser identificados em suas habilidades e passem então a produzir novos saberes uns com os outros.

RPI Revista de Pesquisa Interdisciplinar, Cajazeiras, v. 2, n. 2, 139-148, jun/dez. de 2017. 
Em geral, uma comunidade de prática busca, segundo Palloff e Pratt (2002, p. 48): definir claramente a proposta do grupo; criar um local diferenciado para o grupo; promover lideranças internas eficientes; definir normas e um claro código de conduta; permitir que haja uma variedade de papéis para os membros do grupo; permitir e facilitar subgrupos; permitir que os participantes resolvam suas próprias discussões.

No âmbito da educação, a comunidade de prática e a comunidade de aprendizagem possuem a mesma essência teórica, de modo que uma não difere da outra em praticamente nada tanto que encontramos diversas experiências em educação com a denominação comunidade virtual de prática bem como comunidade virtual de aprendizagem, cada uma delas é provida de suas particularidades. No entanto, asseveramos que o que se propõe expor neste artigo é a Comunidade Virtual de Prática alcançando dimensões mais amplas pois, trata-se de um grupo de educadores que refletem, discutem e, consequentemente, aprendem alicerçados em um movimento dialético e dialógico de reflexão sobre a sua própria prática e tendo como princípio o fazer coletivo.

Para tanto, nos valemos da afirmação de Souza (2005, p.108) “a aprendizagem colaborativa é uma atividade na qual os participantes constroem cooperativamente um modelo explícito de conhecimento", neste sentido, possibilita-nos afirmar que, por se darem em ambientes virtuais sob o regime da colaboração e da socialização, tanto na Comunidade de Prática quanto na Comunidade de Aprendizagem, os sujeitos envolvidos são beneficiados pela possibilidade da autonomia e da interatividade.

Um artigo de uma revista espanhola de educação relata uma experiência interessante de uma comunidade virtual de prática de professores da disciplina de Ciências, segundo García, Greca e Meneses (2008, p.02) a comunidade deveria ser composta de mestres (que teriam que propor temas) e professores especialistas em Ciências, o espaço virtual permitiria que eles realizassem trocas didáticas e metodologias exitosas em suas aulas ou que realizassem criações, propostas, sugestões concretas a fim de que pudesse existir uma inovação curricular mais efetiva. Além disso objetivava resgatar o protagonismo do professorado na inovação curricular, já que as propostas de temas permitiriam ao professor criar, expor suas potencialidades concatenando a teoria e prática. 
Convém explicitar neste momento o universo onde se organiza a nossa atuação, anteriormente já havíamos relatado que a nossa experiência de modelização de uma Comunidade Virtual de Prática está ambientada na Secretaria de Educação do município de Campina Grande - PB, o nosso público alvo compreende um grupo de aproximadamente 250 técnicos educacionais, no entanto, consideramos mais prudente no primeiro momento de implementação e socialização da proposta, focarmos o grupo dos Pedagogos (Supervisores e Orientadores Educacionais), esta decisão advém das especificidades do trabalho pedagógico que orienta a prática dos mesmos e da necessidade de ampliar o tempo/espaço das discussões com o grupo.

Entendemos que à medida que se desenvolve a familiaridade dos usuários com as atividades e possibilidades de interação na plataforma MOODLE, cresce a necessidade de criação de mais grupos diferenciados de discussão e interesses, como também a ampliação do número de mediadores que participam das intervenções. Tendo em vista que a comunidade em pauta é compartilhada por um grupo de pessoas que revelam interesse em partilhar uma prática comum, os Pedagogos partilham os desafios encontrados, novas formas de enfrentamento de determinadas situações, bem como diversas experiências que fazem parte da trajetória de cada profissional, promovendo assim uma reflexão coletiva sobre o trabalho pedagógico em desenvolvimento, com o intuito de potencializar a aprendizagem dos alunos e, consequentemente, melhorar a qualidade da educação do município.

\section{Considerações finais}

Ao traçarmos as linhas finais deste texto nos damos conta do caráter homólogo que estabelecemos com a construção do mesmo. Por meio de um movimento inicial de conversas sobre a nossa prática de formadoras de professores, embora em espaços distintos, alimentamos o desejo e a disponibilidade de pensar o projeto de implementação de uma Comunidade Virtual de Prática objetivando possibilitar a criação de espaços e tempos que ampliassem os encontros formativos com os técnicos educacionais que atuam nas unidades escolares do município de Campina Grande-PB.

Neste sentido, a relação com a experiência se deu na possibilidade de trocas, discussões, interatividade, socialização de experiências, colaboração, enfim, como 
pesquisadoras envolvidas por uma prática comum, porém denotadas de singularidades marcadas pela construção e fazer individual das mesmas que, no entanto, se coadunam no que tem a dizer sobre esse fazer pedagógico, sobre essa experiência prática e que resulta desse diálogo e interatividade, emerge a possibilidade da concretização através da formação de uma Comunidade Virtual de Prática.

Outro aspecto a ser considerado localiza-se nos desafios e possibilidades que a proposta comporta, trata-se de transitar, simultaneamente, entre encontros formativos que vão do presencial ao virtual; de estabelecer parcerias colaborativas; de incorporar na prática a relação com um artefato tecnológico e em rede, que desenvolve de forma ampliada a capacidade de comunicação e interação entre, respectivamente, sujeito e grupo; de, se não romper, mas ao menos permite-se a quebra de paradigmas relativos à formação e constituição de grupos de estudo e discussão; de possibilitar reflexões acerca de como se dá mediações pedagógicas no campo virtual. No entanto, os desafios permanecem e algumas questões, esperamos, poderão ser respondidas futuramente, como por exemplo: as comunidades virtuais de prática possibilitam o desenvolvimento da autonomia, da construção de saberes, das práticas mediadoras e da interatividade nos processos de gestão da educação e da aprendizagem? Qual o impacto destas práticas na qualidade da educação? Entendemos que este trabalho apenas se inicia com este artigo e, a sua contribuição para educação dependerá também da valorização dos sujeitos da educação para que os mesmos se sintam capazes de atuar na construção de novos referenciais para o fazer pedagógico.

\section{Referências}

CASTELLS, Manuel. Paraísos Comunais: identidade e significado na sociedade em rede. In. - O poder da identidade. (A era da informação: economia, sociedade e cultura).Rio de Janeiro: Paz e Terra, 2002.

COELHO, Wilma Baía. A cor ausente:um estudo sobre a presença do negro na formação de professores- Pará, 1970-1989. Belo Horizonte: Editora Unama, 2006.

GOMEZ, Margarita Victoria. Educação em rede: uma visão emancipadora. São

Paulo: Cortez: Instituto Paulo Freire (Guia da escola cidadã; v.11), 2004.

\section{LÉVY, Pierre. AsTecnologias da Inteligência: o futuro do pensamento na era da} informática. Rio de Janeiro: Editora 34, 1993. 
PALLOFF, Rena M.; PRATT, Keith. O aluno virtual: um guia para trabalhar com estudantes on-line Porto Alegre: Artmed, 2004.

Construindo comunidades de aprendizagem no ciberespaço estratégias eficientes para as salas de aula on-line. Porto Alegre: Artmed, 2002.

PERRENOUD, Philippe. A prática reflexiva no ofício de professor:

profissionalização e razão pedagógica. Porto Alegre: Artmed, 2002.

RIBEIRO, Otacílio José. Educação e novas tecnologias: um olhar para além da técnica. In: COSCARELLI, Carla Viana. RIBEIRO, Ana Elisa (orgs). Letramento Digital aspectos sociais e possibilidades pedagógicas. Belo Horizonte: Ceale; Autêntica, 2005.

TAKEUCHI, Hirotaka; NONAKA, Ikujiro. Gestão do conhecimento. Tradução: Ana Thorell. Porto Alegre: Bookman, 2008. 